\title{
SITUAÇÕES DE VULNERABILIDADE A VIOLÊNCIA VIVENCIADAS POR MULHERES PROFISSIONAIS DO SEXO: ESTUDO DE CASO
}

\author{
INSTANCES OF VULNERABILITY TO VIOLENCE EXPERIENCED BY \\ FEMALE SEX WORKERS: A CASE STUDY
}

\section{SITUACIONES DE VULNERABILIDAD A LA VIOLENCIA VIVENCIADA POR TRABAJADORAS SEXUALES: ESTUDIO DE CASO}

\author{
Rubia Geovana Smaniotto Gehlen * \\ Marta Cocco da Costa ${ }^{* *}$ \\ JAQUELINE Arboit ${ }^{* * *}$ \\ Ethel Bastos DA SiLVA ${ }^{* * * *}$
}

\begin{abstract}
RESUMO
Objetivo: Descrever as situações individuais de vulnerabilidade à violência, vivenciadas por mulheres profissionais do sexo. Método: Estudo de abordagem qualitativa cujo método empregado foi o estudo de caso. O cenário da pesquisa foi constituído por duas casas noturnas localizadas em dois municípios do Rio Grande do Sul. A unidade de análise foi composta por oito mulheres profissionais do sexo atuantes nas casas noturnas. Para a coleta das evidências, utilizaram-se entrevistas semiestruturadas, gravações dos áudios em formato MP3, observação do ambiente das casas noturnas e anotações no diário de campo. Para a análise foi utilizada a proposta de adequação ao padrão, tendo em vista as proposições iniciais do estudo. Resultados: Da análise emergiram duas categorias empíricas: caracterização das participantes e das casas noturnas e situações de vulnerabilidade individual à violência vivenciadas no contexto de trabalho das mulheres profissionais do sexo. $\mathrm{O}$ estudo evidenciou que as profissionais do sexo vivenciam a violência pautada nas relações de gênero, permeada por uma relação desigual e hierárquica, exercida por meio do abuso e da força pelos clientes. A carga de violência acontece nas formas física, verbal, sexual e psicológica, sendo o estupro considerado a pior das violências. Conclusão: A saúde das profissionais do sexo não pode ser reduzida a aspectos biológicos, especialmente em relação às doenças sexualmente transmissíveis, sendo necessário considerar o contexto em que as mesmas estão inseridas. Assim, aponta a premência da formulação de políticas públicas no campo da saúde, direcionadas especificamente a esse grupo de mulheres.
\end{abstract}

Palavras chave: Profissionais do sexo; violência; vulnerabilidade; Enfermagem.

Enfermeira. Mestranda em Enfermagem pela Universidade Federal de Santa Maria/UFSM. Membro do Grupo de Pesquisa Cuidado a Saúde das Pessoas, Famílias e Sociedade (GP-PEFAS). Santa Maria (RS), Brasil. Email: rubiageovana@ gmail.com.

${ }^{* *}$ Enfermeira. Professora Doutora em Enfermagem, Universidade Federal de Santa Maria/UFSM. Líder do Grupo de Estudo e Pesquisa em Saúde Coletiva (NEPESC). Palmeira das Missões (RS), Brasil. Email: marta.c.c@ufsm.br

${ }^{* * *}$ Enfermeira. Doutoranda em Enfermagem pela Universidade Federal de Santa Maria/ UFSM. Membro do Grupo de Pesquisa Cuidado a Saúde das Pessoas, Famílias e Sociedade (GP-PEFAS). Santa Maria (RS), Brasil. Email: jaqueline.arboit@ hotmail.com

${ }^{* * * *}$ Enfermeira. Professora Doutora em Enfermagem, Universidade Federal de Santa Maria/UFSM. Líder do Grupo de Estudo e Pesquisa em Saúde Coletiva (NEPESC). Palmeira das Missões (RS), Brasil. Email: ethelbastos@hotmail.com 


\begin{abstract}
Objective: To describe individual situations of vulnerability to violence experienced by female sex workers. Method: A qualitative study in which the method used was the case study. The research setting consisted of two nightclubs located in two municipalities of Rio Grande do Sul. The unit of analysis was composed of eight sex workers working in the nightclubs. For the collection of evidence, we used semi-structured interviews, audio recordings in MP3 format, observation of the nightclub environment and notes in the field diary. For the analysis of the evidence the proposal of adaptation to the standard was used, in view of the initial propositions of the study. Results: From the analysis emerged two empirical categories: characterization of participants and nightclubs, and situations of individual vulnerability to violence experienced in the work context of female sex workers. The study showed that sex workers experience violence based on gender relations, permeated by an unequal and hierarchical relationship, exercised through abuse and force by clients. The burden of violence occurs in physical, verbal, sexual and psychological forms, with rape considered to be the worst form of violence. Conclusion: The health of sex workers cannot be reduced to biological aspects, especially in relation to sexually transmitted diseases, and it is necessary to consider the context in which they are inserted. Thus, the urgency of the formulation of public policies in the field of health is highlighted, directed specifically to this group of women.
\end{abstract}

Key words: Sex workers; violence; vulnerability; Nursing.

\title{
RESUMEN
}

Objetivo: Describir las situaciones individuales de vulnerabilidad a la violencia, vivenciada por mujeres trabajadoras sexuales. Método: Estudio de enfoque cualitativo cuyo método empleado fue el estudio de caso. El escenario de la investigación estuvo constituido por dos casas nocturnas ubicadas en dos municipios de Rio Grande do Sul. La unidad de análisis estuvo compuesta por ocho mujeres trabajadoras sexuales de casas nocturnas. Para la recolección de las evidencias se utilizaron entrevistas semiestructuradas, grabaciones de los audios en formato MP3, observación del ambiente de las casas nocturnas y anotaciones en el diario de campo. Para el análisis de las evidencias se utilizó la propuesta de adecuación al estándar, teniendo en vista las proposiciones iniciales del estudio. Resultados: Del análisis surgieron dos categorías empíricas: caracterización de las participantes y de las casas nocturnas y situaciones de vulnerabilidad individual y violencia vivenciadas en el contexto del trabajo de las mujeres trabajadoras sexuales. El estudio evidenció que las trabajadoras sexuales vivencian la violencia pautada en las relaciones de género, permeada por una relación desigual y jerárquica, ejercida por el abuso y la fuerza por los clientes. La carga de violencia ocurre en las formas físicas, verbal, sexual y psicológica, siendo la violación considerada la peor de las violencias. Conclusión: La salud de las trabajadoras sexuales no puede ser reducida a aspectos biológicos, especialmente en relación a las enfermedades sexualmente transmisibles, siendo necesario considerar el contexto en el que las mismas están insertadas. Así, es urgente la formulación de políticas públicas en el campo de la salud, dirigidas específicamente a ese grupo de mujeres.

Palabras clave: Trabajadoras sexuales; violencia; vulnerabilidad; Enfermería.

Fecha de recepción: 24/05/18 Fecha de aceptación: 04/07/18 


\section{INTRODUÇÃO}

As mulheres, em todos os seus biotipos e contextos, são sujeitos de direitos, e a violação destes pode se dar por meio da violência. Esta é um problema social e de saúde pública, que deve ser compreendida a partir de fatores sociais, históricos e culturais ${ }^{(1-3)}$.

No que diz respeito à violência contra as mulheres profissionais do sexo (PS), esta não pode ser desvinculada da violência contra a mulher ${ }^{(4)}$, uma vez que antes de serem PS, estas são mulheres e precisam ser tratadas como tal. Ambas as violências ancoram-se nas desigualdades de gênero e nas relações de poder, que coloca as mulheres em posição de subalternidade em relação aos homens ${ }^{(5,6)}$. Particularmente em relação às PS, entrecruzam-se estigmas e estereótipos -construídos historicamente- às desigualdades sociais e de gênero, refletindo as mais diversas expressões de violência vivenciadas no cotidiano de trabalho dessas mulheres ${ }^{(5)}$.

Estudos em âmbito do Brasil ${ }^{(5-8)}$ e internacional $^{(9-11)}$ têm apontado as expressões de violência contra as PS, manifestadas sob a forma de violência física, sexual, verbal, moral e psicológica. Tais violências podem desencadear manifestações de ordem psíquicas às PS, cuja taxa de incidência é maior do que na população em geral. Ainda, a carga de violência e vulnerabilidades é expressa não somente pelos sujeitos que compõe o cenário da prostituição, mas também pela sociedade e pelos serviços de saúde ${ }^{(12)}$, diante do estigma e preconceito da profissão.

A mulher estabelece uma relação comercial ao passo que vivencia a prostituição, em que o sexo é o produto a ser negociado ${ }^{(12,13)}$. Nessa direção, em 2002, as PS conquistaram o reconhecimento da sua profissão a partir do registro na Classificação Brasileira de Ocupações com o código no 5198-05, a partir do qual são descritas as atividades exercidas.

Assim, o estudo em tela utiliza o termo "profissionais do sexo", em oposição ao termo "prostitutas”, para fazer referência a essas mulheres, uma vez que este último termo carrega consigo uma carga de preconceito e estigma. Ao encontro dessa abordagem, pesquisadores da temática ${ }^{(14,}$ 15) sinalizam para a necessidade de o trabalho de natureza sexual ser entendido como uma prática laboral, já que o trabalho é compreendido como uma ação humana sobre a natureza, que constrói a identidade do sujeito.

Destaca-se que o cotidiano de trabalho das PS é permeado pelas diversas expressões de vulnerabilidade, a qual é definida ${ }^{(16)}$ como a possibilidade de exposição das pessoas ao adoecimento, resultante de um conjunto que engloba os aspectos individuais, coletivos e contextuais. A vulnerabilidade é caracterizada a partir de três categorias que se inter-relacionam: vulnerabilidade individual, social e programática ${ }^{(16)}$. Destaca-se que o presente estudo terá como objeto as situações de vulnerabilidade individual à violência vivenciadas por PS, uma vez que este componente relaciona-se ao nível de conhecimento que os sujeitos possuem acerca de determinada problemática e das suas habilidades em construir as informações e inseri-las em sua vivência, visando ações protetivas.

Entende-se que esta possibilidade de exposição ao adoecimento irá depender das situações de vida e do cotidiano que predispõem à vulnerabilidade. Desta forma, adota-se o termo situações de vulnerabilidade ${ }^{(17)}$ para definir essas potenciais ameaças ao adoecimento, além de reportar à possibilidade de fuga desses elementos que se configuram como agravos.

A partir do exposto, o estudo teve como questão norteadora: ¿Quais as situações de vulnerabilidade individual à violência vivenciadas por profissionais do sexo? Visando respondê-la, teve como objetivo descrever as situações de vulnerabilidade individual à violência vivenciadas por mulheres profissionais do sexo.

\section{MATERIAL E MÉTODO}

Estudo de abordagem qualitativa cujo método empregado foi o estudo de caso ${ }^{(18)}$, o qual busca a investigação de um fenômeno atual dentro 
do contexto de vida real, principalmente quando não há uma definição entre os limites do fenômeno e do contexto. As proposições teórico-metodológicas do estudo de caso apontam a utilização de diferentes técnicas de levantamento de evidências que direcionam a sua triangulação. Tais proposições são sistematizadas por um protocolo de pesquisa, o que contribui para a confiabilidade e a validade dos achados.

Destaca-se que cada "caso" constitui uma unidade de análise, a qual pode ser um indivíduo, uma organização, um grupo específico, uma comunidade ou até mesmo uma nação. Desta forma, tem-se a possibilidade de desenvolver um estudo de caso único ou estudo de casos múltiplos, em que a unidade de análise é composta por vários indivíduos ou $\operatorname{casos}^{(18)}$. O estudo em tela constitui-se em um estudo de caso múltiplo, em que a unidade de análise foi composta por um grupo específico, possibilitando uma análise mais aprofundada.

O cenário de realização da pesquisa foi constituído por duas casas noturnas localizadas em dois municípios do Rio Grande do Sul. A escolha por estes deu-se em função da necessidade de se conhecer o contexto das PS que trabalham em casas noturnas em cenários distintos, sendo que um dos municípios possui características predominantemente urbanas e o outro menor número de habitantes em relação ao primeiro e características majoritariamente rurais.

Para a realização deste estudo seguiram-se três etapas: a elaboração do protocolo de pesquisa, a coleta das evidências e a categorização e análise dos dados coletados. Assim, inicialmente foi sistematizado o protocolo de pesquisa, mediante questão norteadora da pesquisa, objetivos, exaustivas leituras norteadoras acerca da temática, proposições teóricas; plano de ação/atividades para coleta dos dados; e finalmente a estratégia para categorização e análise dos dados, e elaboração de relatório com triangulação de dados.

Preconiza-se, nos estudos de casos, a investigação de não mais do que dez unidades de análise ${ }^{(18)}$. Assim, a unidade de análise deste estudo foi composta por oito mulheres PS atuantes nas casas noturnas. Como critérios de inclusão elencam-se: ter idade igual ou superior a 18 anos e estar presente na casa no momento da coleta de dados.

Quanto aos procedimentos de coleta de dados, primeiramente foi agendada com o(a) proprietário(a) de cada uma das casas noturnas uma visita que objetivou apresentar o projeto de pesquisa e esclarecer dúvidas. Após, com o consentimento do(a) proprietário(a) e das possíveis participantes, foi agendado previamente dia e horário de modo a não interferir na dinâmica de trabalho e rotina destas.

Para a coleta das evidências, que ocorreu no período de setembro de 2012 a fevereiro de 2013, utilizaram-se as seguintes técnicas: entrevistas semiestruturadas, gravações dos áudios em formato MP3, observação do ambiente das casas noturnas e anotações no diário de campo, conforme preconizado pelo método do estudo de caso.

Para as entrevistas foi desenvolvido um roteiro contendo perguntas abertas e fechadas, dividido em três partes. A primeira relacionada aos dados sociodemográficos e econômicos das mulheres; a segunda aos dados de vulnerabilidade; e a terceira às situações de violência. Foram realizadas de forma individual em local escolhido pelas participantes, tendo duração média de $45 \mathrm{~min}$ e gravadas (áudio) com o consentimento destas.

$\mathrm{Na}$ fase de categorização e classificação dos dados, estabeleceu-se o encadeamento lógico das evidências tendo em vista as proposições teóricas. Para tanto, primeiramente realizou-se a transcrição das entrevistas na íntegra em editor de textos. Após, realizou-se nova escuta dos áudios simultaneamente à leitura das transcrições, para certificar-se que as mesmas foram transcritas integralmente. Em seguida, realizou-se a triangulação dos dados a partir das diferentes fontes de evidências, compondo-se o corpus da pesquisa.

Para a fase de análise das evidências foi utilizada a proposta de adequação ao padrão ${ }^{(18)}$, segundo as proposições teóricas iniciais do estudo e de outras evidências. A interpretação dos achados se deu com a literatura. Da análise dos dados emergiram duas categorias empíricas: Caracteri- 
zação das participantes e das casas noturnas e Situações de vulnerabilidade individual à violência vivenciadas no contexto de trabalho das mulheres profissionais do sexo.

Este estudo respeitou os aspectos éticos da Resolução do Conselho Nacional de Saúde no 466/ 2012 que se aplica a estudos com seres huma$\operatorname{nos}^{(19)}$. Assim, anteriormente a coleta de dados, as mulheres foram esclarecidas acerca dos objetivos da pesquisa por meio do Termo de Consentimento Livre e Esclarecido. As que aceitaram participar o assinaram em duas vias, ficando uma com as participantes e outra com a pesquisadora. Para preservar o anonimato, estas foram identificadas pelo código Casa $\mathrm{A}$, referente à casa noturna urbana e Casa $\mathrm{B}$, referente à casa noturna rural, seguidos do código $\mathrm{P}$ de profissional do sexo e do número sequencial conforme a ordem de realização das entrevistas. O estudo foi apreciado e aprovado por Comitê de Ética em Pesquisa mediante o Certificado de Apresentação para Apreciação Ética (CAAE) no 0381.0.243.000-11.

\section{RESULTADOS}

\section{Caracterização das participantes e das casas no- turnas}

Quanto às PS, estas tinham entre 19 e 35 anos de idade, com média de 25 anos. Destas, quatro estavam solteiras, três eram separadas e uma viúva, todas possuíam um ou mais filhos. Todas naturais de municípios diferentes daquele em que estavam trabalhando. Em relação à escolaridade, cinco possuíam ensino fundamental incompleto; duas, ensino médio completo e uma, ensino médio incompleto. Quanto ao tempo de atuação na profissão, este variou de dois meses a vinte anos, com média de cinco anos. Os relatos evidenciaram que esta prática laboral não é passageira na vida dessas mulheres.

Trabalhei de doméstica e outras coisas, daí vi que não valia a pena [...] que eu ganhava mui- to mais nessa vida do que trabalhando por mês (Casa B P8).

Eu me acostumei em ganhar bem (Casa A P4).

Ambas as casas noturnas se constituem também como o local de moradia das PS, que ganham o quarto para dormir e alimentação. A prática laboral inicia-se a partir das $14 \mathrm{~h}$ e tem seu término ao longo da madrugada. O dinheiro do programa é todo da PS. Quando o cliente deseja realizar o programa fora da casa noturna, o valor torna-se mais oneroso. O proprietário da casa recebe o valor do aluguel do quarto e da bebida consumida pelo cliente e a PS também recebe "gorjeta" sobre o valor das bebidas vendidas.

Em relação às condições habitacionais e de estrutura física, a Casa $\mathrm{B}$ apresentava péssimas condições laborais e de moradia, com uma estrutura física antiga e precária. Para o exercício do trabalho, não havia seguranças realizando a proteção do local, e as mulheres permaneciam a maior parte da noite no ambiente, sozinhas com os clientes, sem a presença do proprietário, situação geradora de medo e angústia.

Quanto mais meninas aqui trabalhando é melhor porque a gente fica mais segura [...] a gente não liga se vai aumentar a concorrência [...] o dono daqui não fica junto de noite e o problema é que tem uns [clientes] que vem armados com revólver, com faca (Casa B P7).

No que diz respeito a Casa A, esta se apresentava em melhores condições, bem estruturada fisicamente e com presença de dois homens realizando a segurança do ambiente durante a noite. Entretanto, a segurança limitava-se somente a área social da casa.

Teve uma vez que ele [um cliente] voou na minha garganta [...] eu abri a porta e sai pelada correndo [...] ele queria sexo anal, tudo sem camisinha (Casa A P5). 


\section{Situações de vulnerabilidade individual à vio- lência vivenciadas no contexto de trabalho das mulheres profissionais do sexo}

No cotidiano do trabalho noturno, o mundo da profissional do sexo passa a ser aquele espaço físico, permeado por situações de vulnerabilidade individual.

É muita briga, a gente nunca sabe se está segura ou não. Às vezes eles [clientes] quebram tudo, daí a gente fica com medo porque nunca sabe o que vai acontecer (Casa B P6).

Uma vez o cara foi paro o quarto comigo, pulou em cima de mim a força, me mordeu toda, me pegou pelo pescoço [...] ficou naquilo mesmo e ele continuou vindo aqui (Casa B P7).

Os achados revelam que as PS frequentemente vivenciam situações de violência sob diferentes formas.

Uma vez me bateram, me amarraram no quarto, me deram soco na boca, me amordaçaram [...] eu não conseguia gritar, pedir ajuda [...] ele me bateu, abusou de mim, fez com força, sexo sem camisinha (Casa B P8).

Tem uns que ficam mordendo o seio da gente ou ficam dando tapa, tem uns até que puxam o cabelo, ou não fazem devagar. Às vezes tem o chupão, mordida (Casa A P3).

Já fui obrigada a fazer coisas que eu não queria, várias vezes [...] é horrível (Casa A P5).

Na medida em que a profissional está a serviço do cliente, estabelece-se uma relação de hierarquização. Diante do risco da agressividade, a profissional busca negociar os termos do programa antes de iniciá-lo, buscando a não violação das regras, bem como prevenir as situações de vulnerabilidade à violência.

O programa tu acerta antes [...] receber no quarto não dá certo porque eles são uns prova- lecidos, depois que tu faz o programa eles não querem te pagar (Casa B P8).

Quando a gente vem para o quarto, antes de tirar a roupa eu digo: agora tu me dá o dinheiro [...], porque tem aqueles que querem aquele faz tudo, e às vezes a gente se encrenca porque não faz (Casa A P1).

As PS expressam que na relação com o cliente, o ser mulher não é considerado, tornando-se objeto de imposição, submissão e exploração.

Tem uns que são uns monstros, que acham que só porque estão pagando têm o direito de fazer o que querem (Casa B P8).

As PS relatam autonomia em realizar o programa dentro ou fora da casa noturna, independente do rendimento financeiro.

Eu não faço programa fora da casa [...] acho muito perigoso [...] aqui (na casa) a gente se sente mais protegida (Casa A P2).

Eu não gosto de sair fora da casa porque te levam por ai e te dão pau, fazem horrores. Uma amiga minha saiu de dentro da casa. Ele pagava 400 o programa [...] no outro dia ela apareceu toda quebrada, roxa e sem dinheiro. Foi horrivel (Casa B P6).

Uma vez eu fui abusada, estuprada, porque fiz o programa e ele não me pagou [...] e ainda me deixou lá no motel para mim me virar e vir embora sozinha [...] quando fui tentar pegar o dinheiro da carteira dele, ele me bateu, fiquei toda roxa e doída (Casa B P7).

Já em relação à autonomia sobre os termos do programa, esta nem sempre consegue ser exercida, o que leva a situações de vulnerabilidade à violência. Nesse contexto, acabam aceitando a violência vivida, por entender que esta faz parte da sua prática laboral.

Tem uns homens que tem que estar batendo na 
gente, dando tapa [...] coisas que a gente tem que passar [...] eles estão pagando e a gente tem que aceitar (Casa B P8).

As faces da violência individual estão retratadas nos relatos das PS. Para essas mulheres, o seu corpo é seu instrumento de trabalho e precisa ser respeitado e valorizado.

Tem uns que são gentis [...] sabem que a mulher tá aqui porque precisa, é um trabalho. Eu tenho vergonha por tudo que a gente acaba tendo que aceitar, mas é um trabalho como qualquer outro, só que a gente trabalha com o corpo, $e$ tem aqueles caras que desvalorizam a gente, tratam como lixo, humilham, ameaçam [...] e tem aqueles que vão reconhecer teu trabalho, pagar bem, tratar com respeito, mas esses são raros (Casa A P3).

Aqui é um trabalho honesto, a gente não está matando, roubando [...] as pessoas dizem 'ah é vida fácil', mas não é fácil nada [...] tem que estar todo dia bebendo [...] a gente dorme mal, come mal e no outro dia tem que beber de novo (Casa B P6).

Dentre as situações de vulnerabilidade a violência, todas as profissionais relataram a vivência do estupro como algo que provoca mais medo na profissão, uma vez que para essas mulheres, este é considerado a forma mais grave de violência.

O estupro, eu tenho muito medo disso (Casa A P3); O estupro é a pior das violências (Casa A P5); O estupro, porque eles fazem o que querem com a gente (Casa B P8).

Quanto ao preservativo, todas as PS relataram não admitir fazer sexo sem camisinha, embora os clientes invistam em tentativas de realizar o programa sem o mesmo.

Quando a gente diz que não faz sexo sem camisinha dai uns começam a gritar, xingar, se revoltam. Tem uns que tiram a camisinha sem a gente ver, mas eu não aceito isso, termino o programa, uns às vezes surtam por causa disso, querem bater na gente (Casa B P7).

O que mais eles pedem é fazer sexo sem camisinha. Mas eu não faço, porque é um meio de trabalho que a gente tem e como a gente vai trabalhar toda errada por dentro (Casa A P5).

Observou-se ambiguidades em relação ao uso do preservativo nos discursos das entrevistadas da Casa A. Para estas, há os clientes fixos que denominam de "amigo" ou "amizade colorida", com os quais há um vínculo estabelecido e o programa caracteriza-se como encontro amoroso, não havendo uso do preservativo. Por outro lado, há o cliente itinerante, sem vínculo afetivo, sendo o uso do preservativo obrigatório.

Em relação ao uso de cigarro, evidenciou-se que todas as mulheres eram tabagistas, já em relação ao álcool e drogas, estes são relatadas como elementos frequentemente presentes nas casas noturnas e durante a realização dos programas.

Eu bebo cerveja na noite, antes e durante os programas, porque a bebida deixa a gente mais solta (Casa B P6).

Tem uns caras que vão para o quarto contigo e não querem transar. Eles querem te drogar. $\mathrm{Pa}$ gam para tu cheirar [...] ver tu louca. [...] eles te obrigam (Casa A P1).

Desta forma, o uso de tais substâncias predispõe às situações de vulnerabilidade a violência, na medida em que alteram o modo de ser e de se comportar dos seus clientes.

Eu tinha um cliente que um dia ele surtou dentro do hotel comigo, de tanto pó que ele usou, queria me matar [...] eu fugi, corri, sai pela porta, saí pedindo socorro (Casa A P4).

\section{DISCUSSÃO}

Todas as participantes relataram o seu ingresso e 
a continuidade como PS como consequência da baixa condição socioeconômica, da necessidade de sobrevivência e superação de dificuldades e da impossibilidade de rendimento financeiro rentável em outras profissões. Uma das mulheres relatou ter ingressado como PS para custear o tratamento médico de seu filho, que veio a falecer. Porém, a mesma permaneceu na profissão por não encontrar em outras a mesma rentabilidade financeira.

Diante disso, infere-se que embora esta seja uma profissão vulnerável, estas mulheres permanecem nesta prática laboral pelo fato de obterem um rendimento financeiro maior do que em outras profissões com baixa ou nenhuma qualificação profissional. Entretanto, ao mesmo tempo em que esta profissão proporciona liberdade financeira e rentabilidade econômica ${ }^{(20)}$, as mulheres passam a conviver com o estigma e o preconceito que a profissão traz consigo nos âmbitos individual e familiar. Neste sentido, todas as mulheres relataram omitir de suas famílias a verdadeira natureza de sua profissão.

O trabalho representa a identidade das pessoas, estrutura o mundo, as relações sociais e as percepções sobre si mesmas e os outros ${ }^{(21-23)}$. Nesse sentido, as profissionais negam a sua identidade, restringem suas relações sociais e alteram as percepções sobre si mesmas e os outros sobre elas, mantendo sua prática laboral e de vida em um universo de anonimato.

Em relação à reduzida escolaridade da maioria das PS deste estudo, esta pode decorrer das dificuldades de acesso à escola e ao abandono, principalmente por mudarem- se de cidade com frequência. $\mathrm{O}$ que configura uma barreira à permanência em instituições de ensino e dificulta a qualificação profissional como perspectiva para mudança de vida ${ }^{(24)}$.

Quanto ao perfil das participantes de ambas as casas, observaram-se algumas semelhanças, como a ausência de cônjuge ou parceiro fixo, condição socioeconômica desfavorável, necessidade de sustentarem a si mesmas e suas famílias e baixo nível de escolaridade. Em relação aos lócus de trabalho, as diferenças estruturais, da dinâmica de trabalho, e rendimento financeiro, ocor- rem em função das características particulares dos municípios em que as casas estão instaladas. Ainda, ambas as casas se constituíam como a moradia das PS, e estas podiam visitar suas famílias quando desejassem.

Observou-se que na Casa A, cujo município tem predominância urbana, a segurança, estrutura física da casa e o rendimento financeiro são melhores. Na Casa B, cujo município tem aspectos predominantes rurais, não há segurança, possui estrutura física precária e o rendimento financeiro do programa é menor. Entretanto, esses aspectos não interferiram no cenário de vulnerabilidades em ambas as casas, demonstrando que a violência acontece independente do ambiente para a prática laboral. Tais achados divergem de resultados de estudos ${ }^{(5-7)}$ que apontam que as profissionais que trabalham nas ruas são as que sofrem maior carga de violência, visto que trabalham em lugares permeados por atos violentos, demonstrando que ambientes fechados também são lócus de situações de violência.

No que concerne ao contexto de trabalho dessas profissionais, este é permeado pelas diversas formas da violência, colocando-as em situações de vulnerabilidade aos agravos decorrentes da mesma. Em relação à violência física, foram citadas, pelos profissionais, empurrões, tapas, espancamentos e mordidas. Quanto à violência sexual, as mais citadas foram ter relação sexual fora dos termos do programa acordado previamente, imposição da prática de sexo sem o uso de camisinha, o não pagamento pelo serviço prestado e o estupro. Na violência verbal citaram-se gritos e insultos. No que se refere à violência psicológica, as profissionais mencionaram humilhações, ameaças a sua integridade física e sexual e a desvalorização do seu trabalho.

Algumas das PS relatam que para as mesmas, o não pagamento do serviço prestado é considerado como estupro, pois implica na utilização do poder e da força, e na forma da violência para romper o acordo entre as partes. Ainda, todas elas atribuíram o estupro como a pior das violências, já que envolve a violência física, sexual e psicológica. Nesse contexto, algumas mulheres se auto-indagaram sobre a subjetividade implicada 
no senso comum de que a profissional do sexo não sofre estupro, pois como poderia ser caracterizado como tal se a mesma está recebendo pelo serviço prestado. Tais indagações refletem o cenário de banalização em que essas PS reconhecem estarem inseridas, e ainda naturalizam a prática da violência a estas, tendo como protagonistas os clientes, proprietários das casas noturnas, e ainda os órgãos protetores, como a polícia.

Este cenário da violência contra a PS está submerso nas desigualdades pautadas nas relações de gênero ${ }^{(25)}$. Desta forma, entende-se que as situações de vulnerabilidade a violência no contexto da relação profissional/cliente também precisam ser vistas a partir da ótica de gênero, uma vez que a profissional passa a estar em situação vulnerável no momento em que se estabelece uma relação de superioridade masculina ${ }^{(6)}$.

No que diz respeito à relação cliente/profissional, esta é fundamentada na hierarquização e subordinação, em que a condução do ato sexual é permeada pela agressividade e imposição dos desejos do cliente/figura masculina. Entretanto, em contraponto a essa questão, reflete-se que a profissional do sexo não vende o seu corpo, mas o aluga, uma vez que algo, quando vendido, passa a pertencer definitivamente para quem o comprou, o que não é o caso das PS ${ }^{(20-26)}$. Esta percepção possibilita desmistificar a ideia de posse do cliente mediante o pagamento, desconstruindo essas relações de poder.

Em relação à autonomia profissional destas mulheres, em ambas as casas as mesmas possuem liberdade para decidir se vão realizar o programa na casa ou fora dela. Entretanto, todas as participantes relataram vivências traumáticas sobre a prática laboral fora do ambiente de trabalho, optando assim por permanecer na casa, mesmo que o programa seja menos oneroso, primando pela sua segurança. Entretanto, embora se sintam mais seguras dentro das casas noturnas, o cenário de vulnerabilidades não diminui ou exime-se. Além disso, a autonomia quanto aos termos do programa, independente do local em que o mesmo ocorre, nem sempre consegue ser exercida, pois muitas vezes ocorre a quebra dos termos do programa, gerando mais situações de vulnerabi- lidade a violência.

Para as mulheres PS, seu corpo é o seu bem mais valioso, e desta forma, a utilização da camisinha nos programas é via de regra, uma vez que para elas, o não uso implica em uma violência ao seu corpo e a sua saúde. Entretanto, da mesma forma, no momento em que ela escolhe não aceitar ter relações sem camisinha, esta atitude também a coloca em situação de vulnerabilidade à violência, ao passo que o cliente acredita que por estar pagando, é de seu direito fazer aquilo que lhe convém com a profissional.

Em contrapartida, o relato de algumas mulheres demonstrou que o uso da camisinha depende do tipo de relação que é estabelecida com o cliente. Corrobora com esses achados, estu$\operatorname{dos}^{(27,28)}$ que sinalizam que o uso do preservativo caracteriza a relação comercial e o não uso conserva o valor simbólico da afetividade. Desta forma, a relação interpessoal estabelecida com o cliente torna-se um determinante para a exposição de situações de vulnerabilidade, uma vez que nenhuma profissional relatou ter sofrido violência perpetrada pelos clientes fixos, com os quais possuem vínculo afetivo.

No que diz respeito ao uso de álcool e substâncias psicoativas, ambos estão presentes na prática laboral das PS como estratégia para encorajamento para realização do programa. Tais substâncias são apontadas por estudos ${ }^{(5-8,29,30)}$ como importante fator de risco para o aumento da violência contra as mulheres PS, pois a necessidade de uso das mesmas condicionam estas mulheres às situações de violência e, consequentemente, também a práticas sexuais não seguras. Em relação ao uso de tabaco, todas as PS do estudo relataram ser fumantes, o que pode ser reflexo do meio em que se encontram, fonte de alívio e prazer.

Frente ao descrito, ressalta-se que, ser profissional do sexo é viver em constante condição de exclusão ${ }^{(20)}$, pois ao passo que estas se inserem neste universo que permeia o mercado sexual, recebem uma marca, um estigma, ou seja, uma identidade deteriorada ${ }^{(31)}$. Assim, o ser mulher e sua essência passam a ser invisíveis, e sua vida pessoal dá lugar ao estereótipo da mulher de 'vida 
fácil', o da prostituta ${ }^{(13)}$. Esta invisibilidade vai ao encontro de que uma das formas mais eficientes de tornar alguém invisível é projetar sobre ele ou ela um estigma, um preconceito ${ }^{(32)}$.

\section{CONCLUSÕES}

O estudo descreveu diversas situações de vulnerabilidade à violência individual que as PS estão expostas continuamente, o que vai de encontro às proposições teóricas iniciais do estudo. Tais situações de vulnerabilidade estão pautadas nas relações de gênero, em que há uma relação desigual entre o cliente e a PS, na qual o primeiro busca exercer sua superioridade por meio do abuso, da força e de diversas outras formas de violência. Nesta direção, identificou-se que as PS sofrem diferentes tipos de violência: física, verbal, psicológica e sexual, sendo o estupro considerado a forma mais grave. Estão vulneráveis ao uso de álcool e drogas, doenças sexualmente transmissíveis, discriminação, preconceito e desvalorização do trabalho, o que consideram formas de violência.

Identificou-se que as situações de vulnerabilidade à violência individual acontecem em diferentes cenários, independente do tipo e lugar do estabelecimento. $\mathrm{O}$ ingresso neste universo dá-se principalmente pelo fator econômico, associado à baixa escolaridade e as dificuldades de acesso à escola e a qualificação profissional.

A guisa de concluir, salienta-se que a atenção à saúde das PS não pode ser reduzida aos aspectos biológicos, sendo necessário considerar o contexto em que a mesma está inserida. As políticas de saúde direcionadas especificamente a essas mulheres e que contemplem as questões da violência são escassas e com inúmeras lacunas. Dessa forma, reconhece-se as limitações deste estudo, sendo necessário direcionar o olhar para a perspectiva da saúde ocupacional, dando seguimento a novas pesquisas que permitam ampliar os achados e respostas às demandas de saúde desse grupo populacional vulnerável, com estudos que contemplem maior número de participantes em diferentes cenários.

\section{REFERÊNCIAS}

1. Guimarães MC, Pedroza RLS. Violência contra a mulher: problematizando definições teóricas, filosóficas e jurídicas. Psicologia \& Sociedade. 2015; 27(2): 256-266.

2. García-Moreno C, Zimmerman C, MorrisGehring A, Heise L, Amin A, Abrahams N, et al. Addressing violence against women: a call to action. Lancet. 2015; 385(9978): 1685-95.

3. Organización Mundial de la Salud (OMS). Violencia contra la mujer [Internet]. Ginebra: OMS; 2017 [citado 24 jun 2018]. Disponível em: http://www.who.int/es/news-room/factsheets/detail/violence-against-women

4. Secretaria de Políticas para as Mulheres. Monitoramento e Acompanhamento da Política Nacional de Atenção Integral à Saúde da Mulher (PNAISM) e do Plano Nacional de Políticas para as Mulheres 2013-2015 (PNPM) [Internet]. Brasília, DF: 2015 [citado 24 oct 2018]. Disponível em: http://www.spm.gov. br/central-de-conteudos/publicacoes/publicacoes/2015/pnaism_pnpm-versaoweb.pdf

5. Lima FSS, Merchán-Hamann E, Urdaneta M, Damacena GN, Szwarcwald CL. Fatores associados à violência contra mulheres profissionais do sexo de dez cidades brasileiras. Cad Saúde Pública [Internet]. 2017 [citado 24 jun 2018]; 33(2): e00157815. Disponível em: http://www.scielo.br/scielo. php?script $=$ sci_arttext $\&$ pid $=$ S0102-311X20 17000205010\&lng $=$ en \&nrm $=$ iso\&tlng $=p t$

6. Silva SG. Preconceito e Discriminação: As Bases da Violência Contra a Mulher. Psicol., Ciênc. Prof. 2010; 30(3): 556-71.

7. Penha JC, Cavalcanti SDC, Carvalho SB, Aquino PS, Furtado DDG, Pinheiro AKB. Caracterização da violência física sofrida por prostitutas do interior piauiense. Rev Bras Enferm. 2012; 65(6): 984-90.

8. Vida CEL, Amara B, Ferreira DP, Dias IMF, Vilela LA, Franco LR. Preditores de prováveis transtornos mentais comuns (TMC) em prostitutas utilizando o Self-Reporting 
Questionnaire. J Bras Psiquiatr. 2014; 63(3): 205-12.

9. Katsulis Y, Durfee A, López V, Robillard A. Predictors of workplace violence among female sex workers in Tijuana, Mexico. Violence Against Women 2015; 21(5): 571-97.

10. Morcillo S. Mujeres invisibles: Políticas del ocultamiento entre mujeres que hacen comercio sexual. Trabajo y Sociedad. 2017; 29: 41-60.

11. Ramírez M, Casis D, Castellano MI, Covarrubias A, Figueroa D, López J, Uribe A, et al. Percepciones corporales en trabajadoras sexuales. Enfermería: Cuidados Humanizados. 2017; 6(1): 37-45.

12. Bortoli V, Costa MC, Silva EB. Violência contra mulheres profissionais do sexo: concepções e ações dos trabalhadores da Atenção Básica. Rev enferm UFPE. 2016; 10(7): 244552.

13. Russo G. No labirinto da prostituição: o dinheiro e seus aspectos simbólicos. Cadernos CRH. 2007; 20(51): 497-514.

14. Silva EFS, Costa D, Nascimento JU. O trabalho das profissionais do sexo em diferentes lócus de prostituição da cidade. Psicol: Teor. Prát. 2010, 12(1): 109-122.

15. MunhozI,NaderTM.Direito das profissionais do sexo em Brasil: análise sobre o Projeto de Lei 4.211 de 2012. Revista ProlegómenosDerechos y Valores. 2014, 17(33):143-158.

16. Ayres JRCM, França Júnior I, Calazans GJ, Saletti Filho HC. O conceito de vulnerabilidade e as práticas de saúde: novas perspectivas e desafios. En: Czeresnia D, Freitas CM, organizadores. Promoção da saúde: conceitos, reflexões, tendências. Rio de Janeiro: Fiocruz; 2003. p. 117-38.

17. Cocco M, Lopes MJM. Violência entre jovens: dinâmicas sociais e situações de vulnerabilidade. Rev Gaúcha Enferm. 2010; 31(1):151-9.

18. Yin RK. Estudo de caso: planejamento e métodos. 5a ed. Porto Alegre: Bookman; 2015.

19. Ministério da Saúde Brasil, Conselho Nacional de Saúde. Resolução No 466, de 12 de Dezembro de 2012. Aprova diretrizes e normas regulamentadoras de pesquisas envolvendo seres humanos. Brasília: Conselho Nacional de Saúde; 2012.

20. Soares JFS, Santos LC, Cardoso JP, Neves L, Batista EC. A Prostituição Como Profissão: Uma Análise Sob a Ótica das Profissionais do Sexo. Rev Saberes. 2015; 3(2): 63-75.

21. Paiva LL, Araújo JL, Nascimento EGC, Alchieri JC. A vivência das profissionais do sexo. Saúde em Debate. 2013; 37(98): 467-476.

22. Zveiter A. A Regulamentação Profissional da Prostituição [Dissertação Mestre]. [Lisboa]: Instituto Universitário de Lisboa; 2017. 100 p.

23. Silva KAT, Cappelle MCA. Sentidos do trabalho apreendidos por meio de fatos marcantes na trajetória de mulheres prostitutas. RAM, Rev. Adm. Mackenzie. 2015; 16(6): 19-47.

24. Sousa FR, Oliveira MW. Deslocamentos no trabalho sexual e seus reflexos na efetivação dos direitos de mulheres prostitutas. Anais do Seminário Internacional Fazendo Gênero 9: Diásporas, Diversidades, Deslocamentos; 23-26 Ago 2010; Santa Catarina: Universidade Federal de Santa Catarina; 2010. p. 1-10.

25. Scott J. Gênero: uma categoria útil para a análise histórica. Educ. Real. 1995; 20(2): 71-99.

26. Silva e Sousa PCJ. Estar disponível, fazer programa e mesmo assim ser invisível: discussão sobre gênero, trabalho e cidadania das/ os prostitutas/os no direito brasileiro [Internet]. XXIII Congresso Nacional do Conselho Nacional de Pesquisa e Pós-graduação (CONPEDI); 05-08 Nov 2014; Paraíba: Universidade Federal da Paraíba, João Pessoa/PB; [citado 13 jul 2017]. Disponível em: http:// publicadireito.com.br/artigos/? cod $=1 \mathrm{~b}$ 984659debd729d

27. Aquino PS, Nicolau AIO, De Souza P, Oliveira AI, Moura ERF, Pinheiro AKB, et al. Perfil sociodemográfico e comportamento sexual de prostitutas de Fortaleza-CE. Texto Contexto Enferm. 2008; 17(3): 427-434.

28. Salmeron NA, Pessoa TAM. Profissionais do sexo: perfil socioepidemiológico e medidas de redução de danos. Acta Paul Enferm. 2012; 25(4): 549-54.

29. Aquino PS, Nicolau AIO, Pinheiro AKB. De- 
sempenho das atividades de vida de prostitutas segundo o Modelo de Enfermagem de Roper, Logan e Tierney. Rev Bras Enferm. 2011; 64(1): 138-144.

30. Di Bonifácio DP, Tilio R. Mulheres profissionais do sexo e o consumo excessivo de álco- ol. Cad. psicol. soc. trab. 2016; 19(1): 29-44.

31. Goffman E. Estigma: notas sobre a manipulação da identidade deteriorada. $4^{a}$ ed. Rio de Janeiro: LTC; 2008. 158 p.

32. Soares LE, Bill MV, Athayde C. Cabeça de Porco. Rio de Janeiro: Objetiva; 2005. P. 175. 